\title{
SDHB loss predicts malignancy in pheochromocytomas/sympathethic paragangliomas, but not through hypoxia signalling
}

\begin{abstract}
Annika Blank ${ }^{1,5 *}$, Anja M Schmitt ${ }^{5 *}$, Esther Korpershoek ${ }^{2}$, Francien van Nederveen ${ }^{2}$, Thomas Rudolph ${ }^{5}$, Nicole Weber ${ }^{3}$, Räto Thomas Strebel ${ }^{4}$, Ronald de Krijger ${ }^{2}$, Paul Komminoth ${ }^{6}$ and Aurel Perren ${ }^{1,5}$
\end{abstract}

\footnotetext{
${ }^{1}$ Institute of Pathology, Klinikum rechts der Isar, Technische Universität München, 81675 Munich, Germany

${ }^{2}$ Department of Pathology, Josephine Nefkens Institute, Erasmus MC, University Medical Center, 3000 CA Rotterdam,

The Netherlands

${ }^{3}$ Department of Pathology, Institute of Surgical Pathology, 8091 Zurich, Switzerland

${ }^{4}$ Department of Urology, University Hospital Zürich, 8091 Zurich, Switzerland

${ }^{5}$ Institute of Pathology, University of Bern, 3012 Bern, Switzerland

${ }^{6}$ Department of Pathology, City Hospital Triemli, 8063 Zurich, Switzerland

(Correspondence should be addressed to A Perren; Email: aurel.perren@pathology.unibe.ch)

*(A Blank and A M Schmitt contributed equally to this work)
}

\begin{abstract}
Prediction of malignant behaviour of pheochromocytomas/sympathetic paragangliomas (PCCs/PGLs) is very difficult if not impossible on a histopathological basis. In a familial setting, it is well known that succinate dehydrogenase subunit $B$ (SDHB)-associated PCC/PGL very often metastasise. Recently, absence of SDHB expression as measured through immunohistochemistry was shown to be an excellent indicator of the presence of an $S D H$ germline mutation in PCC/PGL. SDHB loss is believed to lead to tumour formation by activation of hypoxia signals. To clarify the potential use of SDHB immunohistochemistry as a marker of malignancy in PCC/PGL and its association with classic hypoxia signalling we examined SDHB, hypoxia inducible factor- $1 \alpha$ (Hif- $1 \alpha$ ) and its targets CA-9 and GLUT-1 expression on protein level using immunohistochemistry on a tissue micro array on a series of familial and sporadic tumours of 115 patients. Survival data was available for 66 patients. SDHB protein expression was lost in the tumour tissue of 12 of 99 patients. Of those 12 patients, 5 had an $S D H B$ germline mutation, in 4 patients no germline mutation was detected and mutational status remained unknown in parts in 3 patients. Loss of SDHB expression was not associated with increased classic hypoxia signalling as detected by Hif- $1 \alpha$, CA-9 or GLUT-1 staining. Loss of SDHB expression was associated with an adverse outcome. The lack of correlation of SDHB loss with classic hypoxia signals argues against the current hypoxia hypothesis in malignant PCC/PGL. We suggest SDHB protein loss as a marker of adverse outcome both in sporadic and in familial PCC/PGL.
\end{abstract}

Endocrine-Related Cancer (2010) 17 919-928

\section{Introduction}

Pheochromocytomas (PCCs) are rare tumours of neural crest-derived chromaffin cells. Most tumours arise in the adrenal gland, but up to 23\% (Karagiannis et al. 2007) are localised in extra-adrenal tissue and are called sympathetic paragangliomas (PGLs). About $30 \%$ of these tumours occur in familial tumour syndromes (Neumann et al. 2002, Amar et al. 2005, Tischler 2008, Komminoth 2009) including neurofibromatosis type 1 (NF1), von Hippel-Lindau disease (VHL), multiple endocrine neoplasia type 2 (MEN2) and succinate dehydrogenase (SDH) syndromes. 
The underlying molecular mechanisms leading to PCCs/sympathetic PGLs are not fully understood. Several studies suggest that classic hypoxia signalling involving hypoxia inducible factor- $1 \alpha$ (Hif- $1 \alpha$ ) may play a central role, at least in the context of VHL deficiency (Maxwell et al. 1999). VHL inactivation leads to classic hypoxia signalling by inhibiting the degradation of the Hif- $1 \alpha$ : under normoxic conditions, Hif- $1 \alpha$ is hydroxylated and degraded. Under hypoxia and in some types of cancer it stabilises and accumulates in the nucleus. This leads to an upregulation of the Hif target genes $C A-9$ and GLUT-1 on the one hand and to an increased expression of VEGF, resulting in an increased microvessel density, on the other hand (Couvelard et al. 2005). This mechanism is supported by expression analysis of PCC: on the RNA level, Eisenhofer et al. (2004) described the activation of hypoxia-driven angiogenic pathways in VHL syndrome PCCs. Hif- $1 \alpha$ was not in the list of upregulated genes, possibly because it is regulated on protein rather than on mRNA level (van Uden et al. 2008). Dahia et al. (2005) described a hypoxia-induced expression profile in both $V H L$ and $S D H$-induced PCCs/PGLs. By gain- and lossof-function analyses they additionally suggested that the link between hypoxia signals (through pVHL) and mitochondrial signals (through $\mathrm{SDH}$ ) is mediated by Hif- $1 \alpha$. Succinate accumulating due to $S D H$ mutations can inhibit the degradation of Hif- $1 \alpha$ as do $V H L$ mutations in this in vitro model. This is thought to cause upregulation of Hif targets leading to tumourigenesis (Dahia et al. 2005, Selak et al. 2005, 2006) in SDH-associated PCCs/PGLs. These hopytheses have been challenged by a recent study on hypoxia signalling in hereditary PCCs/PGLs: on mRNA levels there was no difference of Hif- $1 \alpha$ expression between the different tumour types but Hif- $2 \alpha$ was overexpressed in VHL- and SDH-related tumours, a finding that was also reflected by protein expression analysis (Favier et al. 2009). Hif-2 $\alpha$ is reported to be associated with a poor patient outcome in several tumour types (Qing \& Simon 2009). Other results also point towards alternative mechanisms than classic hypoxia signalling: VHL mutants leading to the VHL2c phenotype consisting exclusively of PCCs retain their ability to downregulate Hif (Hoffman et al. 2001). In Caenorhabditis elegans, a subset of genes dysregulated in vhl mutants is not normalised in vhl/hif-1 double mutants (Bishop et al. 2004). Failure of developmental apoptosis may be the hypoxia-independent mechanism of PCC pathogenesis (Lee et al. 2005), possibly with a regulatory loop including Hif (Maxwell 2005).
In the familial setting, it is well known that SDH subunit B (SDHB)-associated PCCs/PGLs very often lead to metastases (Timmers et al. 2007), sometimes many years after resection (Maier-Woelfle et al. 2004). Prediction of malignancy in sporadic tumours is an unsolved problem; the only definite evidence of malignancy is the detection of metastases. The 'PCC of the adrenal gland scaled score (PASS)', a morphological scoring system to identify more aggressive tumours (Thompson 2002), has not proved to be useful due to great interobserver variability in a recent study (Wu et al. 2009). An increased risk of malignancy seems to be indicated by Ki-67 proliferation indices $>2$ or $3 \%$, but this is of limited clinical use (van der Harst et al. 2000, August et al. 2004, Kimura et al. 2005, Strong et al. 2008). Recently, loss of SDHB immunohistochemistry was shown to be an excellent indicator of the presence of an $S D H$ germline mutation in PCCs and PGLs (van Nederveen et al. 2009). Its potential use for predicting biological behaviour is unknown.

To clarify the potential use of SDHB immunohistochemistry as a marker of malignancy and its association with classic hypoxia signalling, we decided to examine SDHB, Hif- $1 \alpha$ and its targets CA-9 and GLUT-1 expression on protein level on a series of familial and sporadic PCCs and sympathetic PGLs and to correlate the results with survival data.

\section{Materials and methods}

\section{Patients and tumour specimens}

All PCCs and sympathetic PGLs analysed at the Institute of Surgical Pathology, University Hospital Zurich in the years from 1975 to 2006 were included.

Clinical data and follow-up information were extracted retrospectively from patient charts. A questionnaire enquiring about tumour relapse or progression was sent to family doctors.

\section{Tumour specimens}

We analysed PCC/PGL specimens from 115 patients (62 males, 46 females and sex could not be evaluated in 7 patients). The available paraffin specimens comprised 112 primary tumours and 3 metastases. Of the 112 primary tumours, 26 were of extra-adrenal abdominal localisation (19 males and 8 females), 76 originated from the adrenal medulla (37 males, 32 females and 7 not specified) and 8 originated extraabdominally. Information about the localisation was not available in two tumours. Of the three metastases one was of an extra-adrenal abdominal primary 
(patient with known $S D H B$ germline mutation), one of an extra-abdominal primary (patient without $S D H B$ germline mutation) and the one metastasis was of an unknown primary (mutational status of the patient unknown). A tissue micro array (TMA) comprising these 115 tissues was constructed as described previously (Bubendorf et al. 2001).

\section{Syndromic patients}

One male patient suffered from NF1 disease clinically, five patients from VHL disease (four with proven $V H L$ mutation, one clinical VHL disease with multiple bilateral clear cell renal cell carcinomas in addition to the PCC (one male, three females and one not specified)) and six patients from MEN2 (proven RET mutation (three males and three females)) (Table 1). An overview of patients and follow-up data is given in Table 2.

\section{Immunohistochemistry}

The analysis was performed on $4 \mu \mathrm{m}$ sections from the TMA, which was stained with antibodies against CA-9, Hif- $1 \alpha$, CD34, GLUT-1 and SDHB. The immunohistochemical staining for the antigens was performed on automated staining systems (CA-9 on Bond Refine, Vision BioSystems Ltd, Newcastle upon Tyne, UK; Hif- $1 \alpha$ on Bond Refine, Vision BioSystems Ltd; CD34 on Ventana BenchMark, Ventana Medical Systems, Tucson, AZ, USA; GLUT-1 on Ventana BenchMark). For SDHB staining, the slides were pretreated by microwave heating in Tris/EDTA buffer, $\mathrm{pH} 9.0$ at $100{ }^{\circ} \mathrm{C}$ for $40 \mathrm{~min}$ or citrate buffer, $\mathrm{pH} 6.0$ for $15 \mathrm{~min}$.
After rinsing in tap water followed by incubation in 3\% $\mathrm{H}_{2} \mathrm{O}_{2}$ in PBS for $15 \mathrm{~min}$ the SDHB antibody was incubated overnight at $4{ }^{\circ} \mathrm{C}$. The presence of tumour tissue was verified by synaptophysin and $\mathrm{H} \& \mathrm{E}$ stainings in all punch cylinders.

The following antibodies were used: CA-9 polyclonal antibody ab15086 (Abcam, Cambridge, UK), dilution 1:200; Hif- $1 \alpha$ monoclonal antibody ab16066 (Abcam), dilution 1:500; GLUT-1 polyclonal antibody AB1341 (Chemicon International, Temecula, CA, USA), dilution 1:1000 and SDHB rabbit polyclonal HPA002868 (Sigma-Aldrich Corp.), dilution 1:250; CD34 clone QBEND/10 (MCAP 547, Serotec, MorphoSys, Oxford, UK), dilution 1:800.

Visualisation was accomplished using the avidinbiotin complex method leading to a brown staining signal. As controls, for SDHB and CD34 endothelial cells served as internal positive control, for CA-9 and GLUT-1 normal liver tissue was used and for Hif- $1 \alpha$ glioblastoma tissue was used.

For CA-9 cytoplasmic and/or membranous staining was scored positive. For Hif- $1 \alpha$ nuclear and cytoplasmic stainings were evaluated separately. For GLUT-1 cytoplasmic staining was scored positive. For Hif- $1 \alpha$ and GLUT-1, depending on the intensity of staining, a semiquantitative scoring system was used, comprising strongly positive, weakly positive and negative immunoreactivities. For CA-9 stainings were scored as either negative or positive. In all stainings tumours with $<5 \%$ positive tumour cells were scored as negative.

SDHB was scored as positive if the cytoplasm showed a strong dot-like positivity. We categorised

Table 1 Results of immunohistochemical hypoxia stainings in familial tumours

\begin{tabular}{|c|c|c|c|c|c|c|}
\hline Patient no. & Syndrome & Sex & Organ & SDHB & Hif-1 $\alpha$ & CA-9 \\
\hline 40 & NF1 & $M$ & Adrenal gland & + & + & - \\
\hline 28 & RET(MEN2) & $M$ & Adrenal gland & + & - & - \\
\hline 39 & RET(MEN2) & $M$ & Adrenal gland & + & - & - \\
\hline 60 & RET(MEN2) & $M$ & Adrenal gland & + & - & - \\
\hline 61 & RET(MEN2) & $\mathrm{F}$ & Adrenal gland & + & - & - \\
\hline 71 & RET(MEN2) & $\mathrm{F}$ & Adrenal gland & + & - & - \\
\hline 117 & RET(MEN2) & $\mathrm{F}$ & Adrenal gland & + & - & - \\
\hline 5 & SDHB & $M$ & Abdominal ea & NA & - & - \\
\hline 11 & SDHB & $M$ & Abdominal ea & - & + & + \\
\hline 33 & SDHB & $\mathrm{F}$ & Abdominal ea & - & - & - \\
\hline 77 & SDHB & $M$ & Abdominal ea & - & - & - \\
\hline 78 & SDHB & $M$ & Abdominal ea & - & - & - \\
\hline 21 & VHL & $M$ & Adrenal gland & NA & - & NA \\
\hline 54 & VHL & $\mathrm{F}$ & Adrenal gland & + & + & + \\
\hline 115 & VHL & $\mathrm{F}$ & Adrenal gland & + & + & - \\
\hline 126 & VHL & UK & Adrenal gland & + & - & - \\
\hline 42 & VHL & $\mathrm{F}$ & Adrenal gland & + & - & - \\
\hline
\end{tabular}

-, no staining; +, positive staining; NA, not assessable; ea, extra-adrenal; UK, unknown. 
Table 2 Clinical characteristics of 115 pheochromocytomas (PCC) patients

\begin{tabular}{|c|c|c|c|c|}
\hline & Total & Men & Women & Unknown \\
\hline Patients & 115 & $62(53.9 \%)$ & $46(40.0 \%)$ & $7(6.1 \%)$ \\
\hline Multifocal & $19(16.5 \%)$ & $11(9.6 \%)$ & $7(6.1 \%)$ & $1(0.9 \%)$ \\
\hline Follow-up available & $66(57.4 \%)$ & $35(30.4 \%)$ & $31(27.0 \%)$ & $0(0 \%)$ \\
\hline Tumour-related death & $15(13.0 \%)$ & $5(4.3 \%)$ & $3(2.6 \%)$ & $7(6.1 \%)$ \\
\hline No tumour-related death/alive & $59(51.3 \%)$ & $30(26.1 \%)$ & $29(25.2 \%)$ & $0(0 \%)$ \\
\hline \multicolumn{5}{|l|}{ Follow-up } \\
\hline Range (month) & $2-291$ & $5-291$ & $2-188$ & - \\
\hline Mean (month) & 78.39 & 77.4 & 79.52 & - \\
\hline Median (month) & 55.5 & 52 & 71 & - \\
\hline \multicolumn{5}{|l|}{ Syndromic patients } \\
\hline NF1 & $1(0.9 \%)$ & $1(0.9 \%)$ & $0(0 \%)$ & $0(0 \%)$ \\
\hline VHL & $5(4.3 \%)$ & $1(0.9 \%)$ & $3(2.6 \%)$ & $1(0.9 \%)$ \\
\hline MEN2 & $6(5.2 \%)$ & $3(2.6 \%)$ & $3(2.6 \%)$ & $0(0 \%)$ \\
\hline SDHB & $5(4.3 \%)$ & $4(3.5 \%)$ & $1(0.9 \%)$ & $0(0 \%)$ \\
\hline \multicolumn{5}{|l|}{ Localisation (primary tumour) } \\
\hline Unknown & $3(2.6 \%)$ & $2(1.7 \%)$ & $1(0.9 \%)$ & $0(0 \%)$ \\
\hline Adrenal & $76(66.1 \%)$ & $37(32.2 \%)$ & $32(27.8 \%)$ & $7(6.1 \%)$ \\
\hline Extra-adrenal & $33(28.7 \%)$ & $22(19.1 \%)$ & $11(9.6 \%)$ & $0(0 \%)$ \\
\hline
\end{tabular}

the tumour as negative if the cytoplasm was negative in the presence of internal positive control in endothelial cells. Tumours with homogeneous faint cytoplasmic staining were scored negative (van Nederveen et al. 2009).

Microvessel density was calculated by counting all vessel sections in tumour tissue of each TMA cylinder with the help of a grid and a counting device in relation to the area consisting of tumour tissue. The number of vessel sections per square millimetre was calculated. Examples of immuohistochemical stainings are given in Fig. 1.

All immunohistochemical stainings were evaluated in a blinded manner by at least two pathologists seperately (A B, A P and F v N).

\section{SDHB mutation analysis}

In patients with negative $S D H B$ immunohistochemistry germline mutation analysis of the $S D H$ genes was performed on peripheral blood or non-neoplastic paraffin tissue after obtaining informed consent. Where no non-neoplastic tissue was available, mutation analysis was performed in tumour tissue. All mutation analyses were performed at least twice in two laboratories (Bern or Zurich and Rotterdam).

DNA was extracted from peripheral blood using the Puregene kit (GentraSystems, Minneapolis, MN, USA) according to the manufacturer's instructions. DNA was extracted from paraffin tissue as described previously (Maier-Woelfle et al. 2004). Mutation analysis was performed by denaturing gradient gel electrophoresisbased mutation analysis as described previously
(Maier-Woelfle et al. 2004). PCRs were repeated for all samples with abnormal banding patterns followed by cycle sequencing. Mutation analysis was repeated in a second laboratory by cycle sequencing in all patients where no SDHB-mutation was detected.

\section{SDHB deletion analysis}

In all SDHB immunonegative cases where no SDHB mutation was detected fluorescence in situ hybridisation (FISH) analysis was performed to detect copy number losses. Deletion analysis was performed by double-target FISH as described before (Schmitt et al. 2009) using a chromosome 1-specific centromere probe in combination with a 1p36.1-1p35-specific probe containing the $S D H B$ gene. Images were recorded with Analysis software (Olympus Biosystems, Hamburg, Germany).

\section{Statistical analysis}

The statistical analysis was performed with SPSS version 16.0.1 (SPSS Software, Chicago, IL, USA). We used two-sided Pearson's $\chi^{2}$-test and Spearman correlation coefficient to analyse dependence of the data. Kaplan-Meier curves were used for demonstration of survival. $P$ values $<0.05$ were considered to indicate statistical significance.

\section{Ethics}

The study was approved by the local ethical committee (Kantonale Ethikkommission, StV 37-2006). 

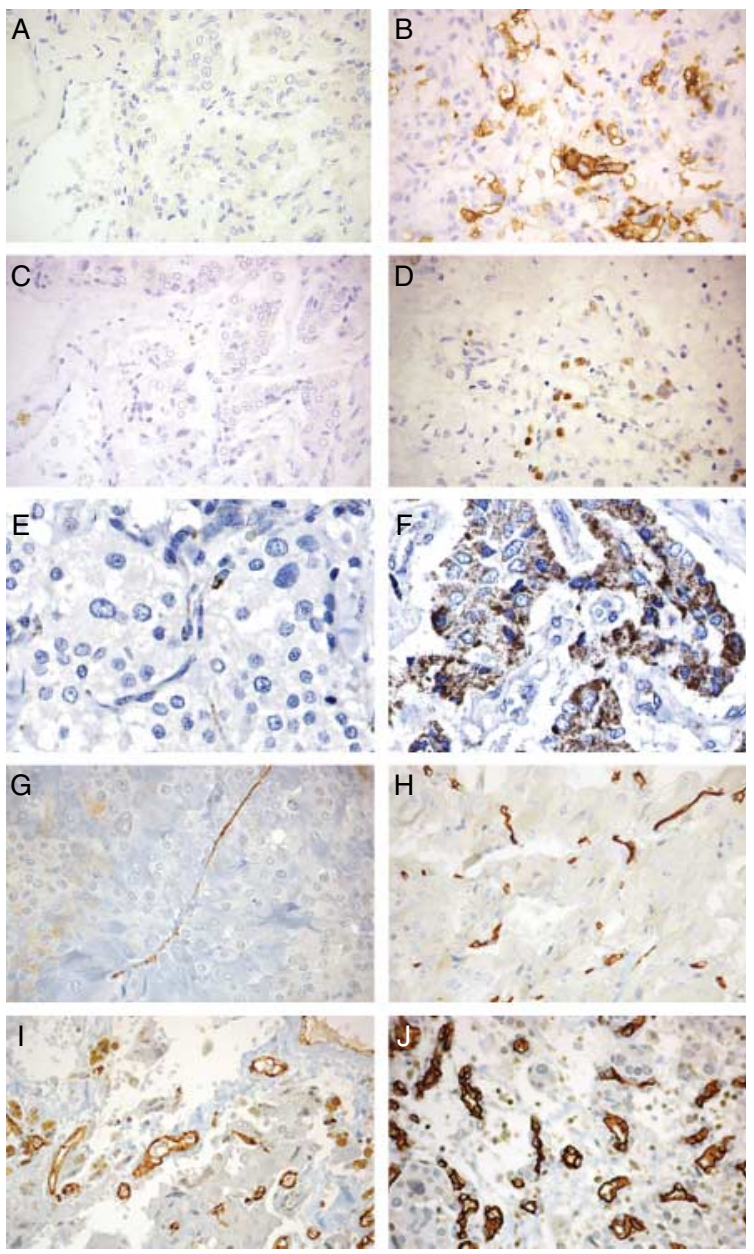

Figure 1 Immunohistochemistry of PCC/PGL. (A) Negative for CA-9; (B) positive for CA-9; (C) nuclear negativity for HIF-1 $\alpha$; (D) nuclear positivity for HIF-1 $\alpha$; (E) negative for SDHB (positive signal in endothelial cells); $(F)$ positive for SDHB (note granular cytoplasmic staining); (G) first quartile microvessel density (MVD); (H) second quartile MVD; (I) third quartile MVD;

(J) fourth quartile MVD.

\section{Results}

\section{Follow-up}

Follow-up data were available for 66 patients (57.4\%). The survival data ranged from 2 to 291 months (mean: 78.39 months; median: 55.5 months). In 15 patients $(13.0 \%)$, death was caused by tumour ( 5 males, 3 females and 7 not specified) (Table 2).

\section{CA-9 immunohistochemistry}

Tumours of 111 patients $(96.5 \%)$ could be evaluated for CA-9 protein expression by immunohistochemistry. In total, $15(13.5 \%)$ of these were scored positive (11 males and 4 females), $96(86.5 \%)$ were negative (48 males, 41 females and 7 without details about sex).

\section{Hif-1 $\alpha$ immunohistochemistry}

Hif- $1 \alpha$ could be evaluated in 114 patients $(99.1 \%)$. Nuclear staining was negative in 110 of $114(96.5 \%)$ patients (60 males, 43 females and sex of 7 patients unknown), only 4 of 114 (3.5\%) patients showed nuclear staining ( 2 males and 2 females).

Regarding cytoplasmic staining, 6 of 114 (5.3\%) showed a strong positive staining (4 males, 1 female and sex of 1 patient unknown) and 14 of 114 (12.3\%) patients were weakly positive ( 6 males, 4 females and sex of 4 patients unknown) whereas the majority of patients (94 of $114,82.5 \%$ ) were negative (52 males, 40 females and sex of 2 patients unknown).

\section{GLUT-1 immunohistochemistry}

GLUT-1 could be evaluated in 112 patients (97.5\%), 6 of them showed a strong positivity ( 3 males, 2 females and sex of 1 patient unknown), 2 showed a strong positivty (1 male and 1 female) and 104 of 112 patients (56 males, 42 females and sex of 6 patients unknown) were negative.

\section{SDHB immunohistochemistry}

SDHB immunohistochemistry could be evaluated in 99 patients $(86.1 \%)$. In 16 patients SDHB immunohistochemistry could not be evaluated due to lack of a positive internal control in the endothelium of the intratumoural vessels. In all, 12 of 99 (12\%) patients were SDHB negative, including all the 5 patients, in whom an $S D H B$ germline mutation was detected (10 males and 2 females); 87 of 99 (87\%) were weakly or strongly positive (41 males, 39 females and 7 unknown). Followup was available for 60 of these 99 patients including 9 of the 12 SDHB immunonegative patients.

Eleven of the 12 (92\%) SDHB-negative tumours were localised outside the adrenal gland (i.e. extraadrenal sympathetic PGLs).

Three of the 12 (25\%) SDHB-negative tumours showed a strong positivity in the CA-9 staining, and 9 (75\%) were negative (not significant in cross tabulation).

None of the SDHB-negative patients showed a strong nuclear positivity for Hif- $1 \alpha$, all 12 were negative for Hif- $1 \alpha$ in the nucleus. Two (17\%) SDHB-negative patients showed a strong cytoplasmic positivity for Hif- $1 \alpha, 1(8 \%)$ was weakly positive and 9 (75\%) were negative for Hif- $1 \alpha$.

\section{Mutation status in SDHB-negative tumours}

In two brothers an $S D H B$ germline mutation was already known. Mutation analysis of the $S D H B, S D H C$ and $S D H D$ genes was performed in all the remaining 10 patients. $S D H B$ germline mutation was excluded in 
one patient by analysing non-neoplastic tissue. In three additional patients SDHB mutations were excluded in tumour tissues as no non-neoplastic tissue was available. In the remaining three patients SDHB mutations could be excluded in parts of the $S D H B$ gene in tumour tissue, the remaining exons were not amplifiable (Table 3). All patients without an $S D H B$ germline mutation were tested for $S D H C$ and $S D H D$ mutations. $S D H C$ mutations were absent in all three informative patients and $S D H D$ mutations were absent in all five informative patients.

\section{Microvessel density}

In 109 evaluable cases the number of vessel sections in the area of the cylinder $\left(0.28 \mathrm{~mm}^{2}\right)$, corrected for nonneoplastic portions if present, ranged from 3.75 to 1144 (mean 229 and median 122). Tumours were subdivided into quartiles according to the number of vessel sections per $\mathrm{mm}^{2}$. The first quartile ranged from 13 to 535 vessel sections per $\mathrm{mm}^{2}$, the second from 548 to 1083 vessel sections per $\mathrm{mm}^{2}$, the third from 1268 to 1530 vessel sections per $\mathrm{mm}^{2}$ and the fourth from 1641 to 4046 vessel sections per $\mathrm{mm}^{2}$.

\section{SDHB deletion analysis}

In seven SDHB immunonegative cases without a detectable $S D H$ mutation SDHB deletion analysis was performed by FISH. One SDHB immunonegative case with an $S D H B$ germline mutation and a known deletion served as a positive control. In five of these seven SDHB immunonegative cases no SDHB deletion was detected. Two cases were not evaluable in repeated analyses.

\section{Statistical analysis}

SDHB immunoreactivity did neither correlate with cytoplasmic CA-9 staining $\left(P=0.150 ; r_{\mathrm{s}}=0.000\right)$ nor with nuclear or cytoplasmic Hif- $1 \alpha$ staining $\left(P=0.555 ; r_{\mathrm{s}}=0.109\right.$ and $P=0.399 ; r_{\mathrm{s}}=-0.010$ respectively) nor with GLUT-1 $\left(P=0.780 ; r_{\mathrm{s}}=0.083\right)$.

Significant correlation was observed between both nuclear and cytoplasmic Hif- $1 \alpha$ immunoreactivity and CA-9 staining $\left(P=0.000 ; r_{\mathrm{s}}=0.348\right.$ and $P<0.000$; $r_{\mathrm{s}}=0.123$ respectively).

Survival analysis was performed for all immunohistochemical markers. The survival of patients with SDHB immunonegative tumours was significantly adverse compared with SDHB-positive tumours

Table 3 Clinical characteristics of SDHB immunonegative tumours

\begin{tabular}{|c|c|c|c|c|c|c|c|c|}
\hline PGL-no. & Sex & Syndrome & SDHB mutation & Tumour & $\begin{array}{l}\text { Localisation of } \\
\text { primary tumour }\end{array}$ & $\begin{array}{l}\text { Localisation } \\
\text { of metastasis }\end{array}$ & $\begin{array}{l}\text { Multi- } \\
\text { focal }\end{array}$ & $\begin{array}{l}\text { Follow-up } \\
\text { (age at time } \\
\text { of death) }\end{array}$ \\
\hline aPGL001 & M & No & All ex neg (tu) & $\begin{array}{l}\text { Primary } \\
\text { tumour }\end{array}$ & $\begin{array}{l}\text { Abdominal } \\
\text { ea/paraaortal }\end{array}$ & No & No & AWD \\
\hline aPGL007 & M & SDHB & $\begin{array}{l}\text { Del 632G } \\
\quad \text { in Exon } 5\end{array}$ & Metastasis & $\begin{array}{l}\text { Abdominal } \\
\text { ea/pararenal }\end{array}$ & Spine & No & DOD (37) \\
\hline aPGL030 & M & No & $\begin{array}{l}\text { All ex neg. } \\
\text { (tu+nnt) }\end{array}$ & $\begin{array}{l}\text { Primary } \\
\text { tumour }\end{array}$ & $\begin{array}{l}\text { Abdominal } \\
\text { ea/pararenal }\end{array}$ & $\begin{array}{l}\text { Liver, bones, } \\
\text { lymph nodes }\end{array}$ & No & DOD (62) \\
\hline aPGL031 & M & SDHB & $\begin{array}{l}\text { C. } 307 \text { insC/ } \\
\text { p.103 Trp fs }\end{array}$ & $\begin{array}{l}\text { Primary } \\
\text { tumour }\end{array}$ & $\begin{array}{l}\text { Abdominal } \\
\text { ea/paraaortal }\end{array}$ & & No & NA \\
\hline aPGL047 & M & No & $\begin{array}{l}\text { Ex } 4 / 6 \text { neg. } \\
\text { remaining } \\
\text { NA (tu) }\end{array}$ & $\begin{array}{l}\text { Primary } \\
\text { tumour }\end{array}$ & Adrenal gland & No & No & NA \\
\hline aPGL058 & M & No & $\begin{array}{r}\text { Ex 1/2/3/4/5/6/7 } \\
\text { neg, } 8 \text { NA (tu) }\end{array}$ & $\begin{array}{l}\text { Primary } \\
\text { tumour }\end{array}$ & $\begin{array}{l}\text { Abdominal } \\
\text { ea/paraaortal }\end{array}$ & $\begin{array}{l}\text { Aorta, small } \\
\text { bowel, bones }\end{array}$ & Yes & AWD \\
\hline aPGL091 & $\mathrm{F}$ & SDHB & $\begin{array}{l}\text { Del } 632 \mathrm{G} \\
\quad \text { in Exon } 5\end{array}$ & $\begin{array}{l}\text { Primary } \\
\text { tumour }\end{array}$ & $\begin{array}{l}\text { Abdominal } \\
\text { ea/pararenal }\end{array}$ & No & No & AWD \\
\hline aPGL204 & M & SDHB & H132P & $\begin{array}{l}\text { Primary } \\
\text { tumour }\end{array}$ & $\begin{array}{l}\text { Abdominal } \\
\text { ea/paraaortal }\end{array}$ & Lymph nodes & No & DOD (43) \\
\hline aPGL205 & M & SDHB & $\mathrm{H} 132 \mathrm{P}$ & Metastasis & $\begin{array}{l}\text { Abdominal } \\
\text { ea/paraaortal }\end{array}$ & Bones & Yes & DOD (60) \\
\hline aPGL243 & $\mathrm{F}$ & No & All ex neg. (tu) & Metastasis & Mediastinal & Brain & Yes & DOD (56) \\
\hline aPGL320 & M & No & $\begin{array}{c}\text { Ex } 1 / 2 / 4 / 5 / 6 \\
\text { neg (tu) }\end{array}$ & $\begin{array}{l}\text { Primary } \\
\text { tumour }\end{array}$ & $\begin{array}{l}\text { Abdominal } \\
\text { ea/paraaortal }\end{array}$ & No & No & AWD \\
\hline aPGL347 & M & No & Ex 6 neg. (tu) & $\begin{array}{l}\text { Primary } \\
\text { tumour }\end{array}$ & $\begin{array}{l}\text { Abdominal } \\
\text { ea/paraaortal }\end{array}$ & No & Yes & NA \\
\hline
\end{tabular}

SDHB, succinate dehydrogenase subunit B; Del, deletion; ins, insertion; ea, extra-adrenal; NA, not assessable; tu, tumour; nnt, non-neoplastic tissue; AWD, alive with disease; DOD, death of disease. 


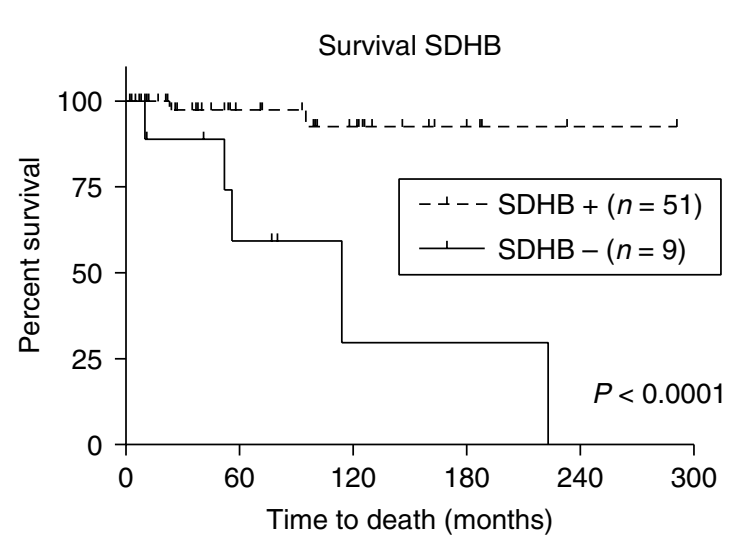

Figure 2 Kaplan-Meier curve depicting percentage of tumourspecific survival for PCC/PGL with (upper curve) and without (lower curve) SDHB immunoreactivity.

$(P<0.0001$; Fig. 2). No survival difference between a weak and strong SDHB positivity was found. An extraadrenal localisation of the primary tumour was also associated with a shortened tumour-specific survival $(P=0.005)$. The survival depending on hypoxia markers CA-9, Hif- $1 \alpha$ or GLUT-1 offered no significant trend.

Increased microvessel density correlated significantly with loss of SDHB $\left(P=0.017 ; r_{\mathrm{s}}=-0.289\right)$ but not with Hif- $1 \alpha$ in the nucleus $(P=0.192$; $\left.r_{\mathrm{s}}=0.171\right)$, Hif $-1 \alpha$ in the cytoplasm $\left(P=0.496 ; r_{\mathrm{s}}=\right.$ 0.048), GLUT-1 $\left(P=0.990 ; r_{\mathrm{s}}=-0.040\right)$ and CA-9 $\left(P=0.186 ; r_{\mathrm{s}}=0.070\right)$. An overview over the correlation results is given in Table 4.

\section{Discussion}

Prediction of malignant behaviour of PCCs is very difficult if not impossible on a histopathological basis. A proposed morphological scoring scheme did not prove useful in a recent analysis due to large interobserver variablility (Thompson 2002, Kimura et al.
2005, Wu et al. 2009). The present survival analysis on 66 unselected PCC/sympathetic PGL patients with follow-up revealed SDHB immunohistochemistry as a possible prognostic marker. The survival of patients with SDHB immunonegative tumours was significantly worse than of patients with SDHBpositive tumours. Five of nine patients with SDHB immunonegative tumours and available follow-up died because of the tumours; of those five patients three had an $S D H B$ germline mutation. A tumour-related death did not occur in the six strongly SDHB-positive tumours and only twice in the 46 weakly SDHBpositive tumours with available follow-up. A possible explanation of these findings is that the SDHBnegative tumours arise in patients with the SDHBassociated PCC/PGL syndrome. Indeed, we could demonstrate an $S D H B$ germline mutation in five of the nine immunonegative patients we were able to examine. $S D H B$ mutations were excluded in all coding regions of four patients. We were only able to exclude $S D H B$ mutations in the remaining three immunonegative patients in a minority of SDHB exons. In tumours with $S D H B$ germline mutation inactivation of the wild-type allele occurs by loss of heterozygosity (LOH) (Gimenez-Roqueplo et al. 2002, Maier-Woelfle et al. 2004); we were able to exclude such LOH by FISH analysis in five of the seven immunonegative cases without germline mutation. SDHB germline deletions are described in up to $30 \%$ of SDHB kindreds (McWhinney et al. 2004, Tischler 2008). In these tumours LOH would also be expected. Therefore, we postulate that at least these five patients with SDHB immunonegative tumours without mutation or deletion suffer from sporadic disease. van Nederveen et al. (2009) described SDHB loss by immunohistochemistry in $11-16 \%$ of sporadic tumours, a similar frequency as described in this study. Complete loss of granular SDHB immunopositivity has been shown

Table 4 Correlations and correlation coefficient of immunohistochemistry and number of vessels

\begin{tabular}{|c|c|c|c|c|c|c|}
\hline & $\begin{array}{c}\text { Hif-1 } \alpha \\
\text { nucleus }\end{array}$ & $\begin{array}{c}\text { Hif-1 } \alpha \\
\text { cytoplasma }\end{array}$ & SDHB & GLUT1 & $\begin{array}{c}\text { Number of } \\
\text { vessels }\end{array}$ & Localisation \\
\hline CA9 & 0.000 & 0.000 & 0.150 & 0.834 & 0.186 & 0.406 \\
\hline Spearman correlation & 0.348 & 0.123 & 0.000 & -0.006 & -0.070 & \\
\hline Hif- $1 \alpha$ nucleus & & 0.643 & 0.555 & 0.853 & 0.192 & 0.291 \\
\hline Spearman correlation & & -0.088 & 0.109 & -0.053 & 0.171 & \\
\hline Hif- $1 \alpha$ cytoplasma & & & 0.399 & 0.301 & 0.496 & 0.174 \\
\hline Spearman correlation & & & -0.010 & 0.148 & 0.048 & \\
\hline SDHB & & & & 0.780 & 0.017 & 0.000 \\
\hline Spearman correlation & & & & 0.083 & -0.289 & \\
\hline GLUT1 & & & & & 0.990 & 0.665 \\
\hline Spearman correlation & & & & & -0.40 & \\
\hline
\end{tabular}

$P$ values bold numbers indicate statistical significance. 


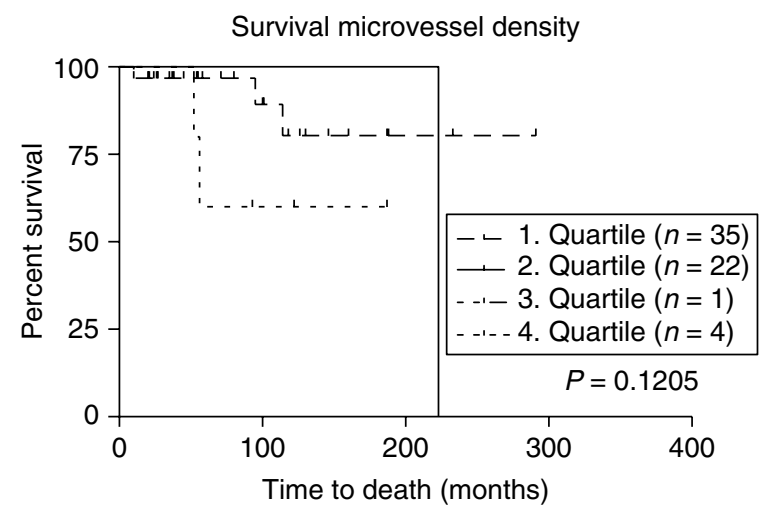

Figure 3 Kaplan-Meier curve depicting percentage of tumourspecific survival for PCC/PGL in dependence of microvessel density (displayed in quartiles). There is no significant correlation between microvessel density and survival.

as a predictor of $S D H$ germline mutation with a positive predictive value of at least $92 \%$ and a negative predictive value of $100 \%$ (van Nederveen et al. 2009). In our series, both tumours with a known $S D H$ germline mutation stained negative for SDHB immunohistochemistry, confirming the high negative predictive value of a positive SDHB staining. From the clinical point of view our data also stress the role of localisation of the tumour. In our series there was a strong correlation of extra-adrenal localisation with poor prognosis and $S D H B$ germline mutation, which is in line with previous findings (Neumann et al. 2002, Maier-Woelfle et al. 2004, Amar et al. 2005, Lenders et al. 2005, Tischler 2008).

One aim of our study was to examine the possible link between SDHB immunostaining, which is indicative of enzymatic activity of the SDH complex (van Nederveen et al. 2009) with classic hypoxia signalling, as suggested by several authors (Dahia et al. 2005, Pollard et al. 2006). Classic hypoxia signalling through Hif- $1 \alpha$ and its target genes $C A-9$ and GLUT-1 plays a central role in the development of clear cell renal cell carcinoma and glioblastoma (Kaelin 2004, Kaur et al. 2005). Thus, we examined the expression of Hif-1 $\alpha$, CA-9 and GLUT-1 by immunohistochemistry. Classic hypoxia signalling as characterised by an accumulation of these proteins in our study could be detected only in a small minority of tumours and did not have any influence on survival. There was no association of SDHB loss with CA-9, GLUT-1 and Hif- $1 \alpha$ protein level. In contrast, SDHB protein loss correlated with a high microvessel density. Moreover, SDHB loss correlated with an adverse outcome, while a high microvessel density did not significantly correlate with a poor survival (Fig. 3). The two markers of classical hypoxia, Hif- $1 \alpha$ and CA-9, showed a strong correlation with each other, arguing against technical problems in identifying classic hypoxia signals. These findings argue against an important role of classic hypoxia signalling in the development of PCCs/PGLs. However, pseudohypoxia, which is mediated by Hif$2 \alpha$, might play a role as suggested by Favier et al. (2009) who found a high Hif- $2 \alpha$ expression in both VHL- and SDH-associated PCCs. However, while the same authors described an upregulation of glucose transporters solely in VHL-associated PCC we cannot confirm these findings: in our study all VHL-associated cases were immunonegative for GLUT-1.

Alternatively, other mechanisms than pseudohypoxia signals might be involved in the genesis of SDHB-associated and most sporadic PCCs even in the setting of the VHL syndrome, such as apoptosis and inhibition of microtubule stabilisation as suggested by other authors (Hergovich et al. 2003, Lee et al. 2005). Further studies will be needed to elucidate the mechanisms of tumourigenesis in PCCs/PGLs.

In summary, we suggest SDHB protein loss as a marker of adverse outcome both in sporadic and in familial PCCs/PGLs. Inclusion of this marker in the assessment of PCCs/PGLs might be mandatory for two reasons: first, for direction of molecular genetic testing towards the $S D H$ genes in the case of absent staining, and second as a prognostic marker. We suggest to include patients with sporadic SDHB-negative tumours in more stringent follow-up protocols.

\section{Declaration of interest}

The authors declare that there is no conflict of interest that could be perceived as prejudicing the impartiality of the research reported.

\section{Funding}

This research did not receive any specific grant from any funding agency in the public, commercial or not-for-profit sector.

\section{References}

Amar L, Bertherat J, Baudin E, Ajzenberg C, Bressac-de Paillerets B, Chabre O, Chamontin B, Delemer B, Giraud S, Murat A et al. 2005 Genetic testing in pheochromocytoma or functional paraganglioma. Journal of Clinical Oncology 23 8812-8818. (doi:10.1200/JCO.2005.03. 1484)

August C, August K, Schroeder S, Bahn H, Hinze R, Baba HA, Kersting C \& Buerger H 2004 CGH and CD 44/MIB1 immunohistochemistry are helpful to distinguish 
metastasized from nonmetastasized sporadic pheochromocytomas. Modern Pathology 17 1119-1128. (doi:10. 1038/modpathol.3800160)

Bishop T, Lau KW, Epstein AC, Kim SK, Jiang M, O'Rourke D, Pugh CW, Gleadle JM, Taylor MS, Hodgkin J et al. 2004 Genetic analysis of pathways regulated by the von Hippel-Lindau tumor suppressor in Caenorhabditis elegans. PLoS Biology 2 e289. (doi:10.1371/journal.pbio. 0020289)

Bubendorf L, Nocito A, Moch H \& Sauter G 2001 Tissue microarray (TMA) technology: miniaturized pathology archives for high-throughput in situ studies. Journal of Pathology 195 72-79. (doi:10.1002/path.893)

Couvelard A, O'Toole D, Turley H, Leek R, Sauvanet A, Degott C, Ruszniewski P, Belghiti J, Harris AL, Gatter K et al. 2005 Microvascular density and hypoxia-inducible factor pathway in pancreatic endocrine tumours: negative correlation of microvascular density and VEGF expression with tumour progression. British Journal of Cancer 92 94-101. (doi:10.1038/sj.bjc.6602245)

Dahia PL, Ross KN, Wright ME, Hayashida CY, Santagata S, Barontini M, Kung AL, Sanso G, Powers JF, Tischler AS et al. 2005 A HIF1alpha regulatory loop links hypoxia and mitochondrial signals in pheochromocytomas. PLoS Genetics 1 72-80. (doi:10.1371/journal.pgen.0010008)

Eisenhofer G, Huynh TT, Pacak K, Brouwers FM, Walther MM, Linehan WM, Munson PJ, Mannelli M, Goldstein DS \& Elkahloun AG 2004 Distinct gene expression profiles in norepinephrine- and epinephrine-producing hereditary and sporadic pheochromocytomas: activation of hypoxia-driven angiogenic pathways in von HippelLindau syndrome. Endocrine-Related Cancer 11 897-911. (doi:10.1677/erc.1.00838)

Favier J, Briere JJ, Burnichon N, Riviere J, Vescovo L, Benit P, Giscos-Douriez I, De Reynies A, Bertherat J, Badoual C et al. 2009 The Warburg effect is genetically determined in inherited pheochromocytomas. PLoS ONE 4 e7094. (doi:10.1371/journal.pone.0007094)

Gimenez-Roqueplo AP, Favier J, Rustin P, Rieubland C, Kerlan V, Plouin PF, Rotig A \& Jeunemaitre X 2002 Functional consequences of a SDHB gene mutation in an apparently sporadic pheochromocytoma. Journal of Clinical Endocrinology and Metabolism 87 4771-4774. (doi:10.1210/jc.2002-020525)

van der Harst E, Bruining HA, Jaap Bonjer H, van der Ham F, Dinjens WN, Lamberts SW, de Herder WW, Koper JW, Stijnen T, Proye C et al. 2000 Proliferative index in phaeochromocytomas: does it predict the occurrence of metastases? Journal of Pathology 191 175-180. (doi:10. 1002/(SICI)1096-9896(200006)191:2 < 175::AID-

PATH615 > 3.0.CO;2-Z)

Hergovich A, Lisztwan J, Barry R, Ballschmieter P \& Krek W 2003 Regulation of microtubule stability by the von Hippel-Lindau tumour suppressor protein pVHL. Nature Cell Biology 5 64-70. (doi:10.1038/ncb899)

Hoffman MA, Ohh M, Yang H, Klco JM, Ivan M \& Kaelin WG Jr 2001 von Hippel-Lindau protein mutants linked to type $2 \mathrm{C}$ VHL disease preserve the ability to downregulate HIF. Human Molecular Genetics 10 1019-1027. (doi:10. 1093/hmg/10.10.1019)

Kaelin WG Jr 2004 The von Hippel-Lindau tumor suppressor gene and kidney cancer. Clinical Cancer Research 10 6290S-6295S. (doi:10.1158/1078-0432. CCR-sup-040025)

Karagiannis A, Mikhailidis DP, Athyros VG \& Harsoulis F 2007 Pheochromocytoma: an update on genetics and management. Endocrine-Related Cancer 14 935-956. (doi:10.1677/ERC-07-0142)

Kaur B, Khwaja FW, Severson EA, Matheny SL, Brat DJ \& Van Meir EG 2005 Hypoxia and the hypoxia-induciblefactor pathway in glioma growth and angiogenesis. Neuro-Oncology 7 134-153. (doi:10.1215/ S1152851704001115)

Kimura N, Watanabe T, Noshiro T, Shizawa S \& Miura Y 2005 Histological grading of adrenal and extra-adrenal pheochromocytomas and relationship to prognosis: a clinicopathological analysis of 116 adrenal pheochromocytomas and 30 extra-adrenal sympathetic paragangliomas including 38 malignant tumors. Endocrine Pathology 16 23-32. (doi:10.1385/EP:16:1:023)

Komminoth P, Perren A, van Nederveen FH \& Krijger RR 2009 Familial endocrine tumours: phaeochromocytomas and extra-adrenal paragangliomas. Diagnostic Histopathology 15 61-68. (doi:10.1016/j.mpdhp.2009.01.003)

Lee S, Nakamura E, Yang H, Wei W, Linggi MS, Sajan MP, Farese RV, Freeman RS, Carter BD, Kaelin WG Jr et al. 2005 Neuronal apoptosis linked to EglN3 prolyl hydroxylase and familial pheochromocytoma genes: developmental culling and cancer. Cancer Cell $\mathbf{8}$ 155-167. (doi:10.1016/j.ccr.2005.06.015)

Lenders JW, Eisenhofer G, Mannelli M \& Pacak K 2005 Phaeochromocytoma. Lancet 366 665-675. (doi:10.1016/ S0140-6736(05)67139-5)

Maier-Woelfle M, Brandle M, Komminoth P, Saremaslani P, Schmid S, Locher T, Heitz PU, Krull I, Galeazzi RL, Schmid C et al. 2004 A novel succinate dehydrogenase subunit B gene mutation, H132P, causes familial malignant sympathetic extraadrenal paragangliomas. Journal of Clinical Endocrinology and Metabolism 89 362-367. (doi:10.1210/jc.2003-031236)

Maxwell PH 2005 A common pathway for genetic events leading to pheochromocytoma. Cancer Cell 8 91-93. (doi:10.1016/j.ccr.2005.07.012)

Maxwell PH, Wiesener MS, Chang GW, Clifford SC, Vaux EC, Cockman ME, Wykoff CC, Pugh CW, Maher ER \& Ratcliffe PJ 1999 The tumour suppressor protein VHL targets hypoxia-inducible factors for oxygen-dependent proteolysis. Nature 399 271-275. (doi:10.1038/20459)

McWhinney SR, Pilarski RT, Forrester SR, Schneider MC, Sarquis MM, Dias EP \& Eng C 2004 Large germline deletions of mitochondrial complex II subunits SDHB and SDHD in hereditary paraganglioma. Journal of Clinical Endocrinology and Metabolism 89 5694-5699. (doi:10. 1210/jc.2004-0769) 
van Nederveen FH, Gaal J, Favier J, Korpershoek E, Oldenburg RA, de Bruyn EM, Sleddens HF, Derkx P, Riviere J, Dannenberg H et al. 2009 An immunohistochemical procedure to detect patients with paraganglioma and phaeochromocytoma with germline SDHB, SDHC, or SDHD gene mutations: a retrospective and prospective analysis. Lancet Oncology 10 764-771. (doi:10.1016/ S1470-2045(09)70164-0)

Neumann HP, Bausch B, McWhinney SR, Bender BU, Gimm O, Franke G, Schipper J, Klisch J, Altehoefer C, Zerres K et al. 2002 Germ-line mutations in nonsyndromic pheochromocytoma. New England Journal of Medicine 346 1459-1466. (doi:10.1056/ NEJMoa020152)

Pollard PJ, El-Bahrawy M, Poulsom R, Elia G, Killick P, Kelly G, Hunt T, Jeffery R, Seedhar P, Barwell J et al. 2006 Expression of HIF-1alpha, HIF-2alpha (EPAS1), and their target genes in paraganglioma and pheochromocytoma with VHL and SDH mutations. Journal of Clinical Endocrinology and Metabolism 91 4593-4598. (doi:10.1210/jc.2006-0920)

Qing G \& Simon MC 2009 Hypoxia inducible factor-2alpha: a critical mediator of aggressive tumor phenotypes. Current Opinion in Genetics \& Development 19 60-66. (doi:10.1016/j.gde.2008.12.001)

Schmitt AM, Schmid S, Rudolph T, Anlauf M, Prinz C, Kloppel G, Moch H, Heitz PU, Komminoth P \& Perren A 2009 VHL inactivation is an important pathway for the development of malignant sporadic pancreatic endocrine tumors. Endocrine-Related Cancer 16 1219-1227. (doi:10.1677/ERC-08-0297)

Selak MA, Armour SM, MacKenzie ED, Boulahbel H, Watson DG, Mansfield KD, Pan Y, Simon MC, Thompson CB \& Gottlieb E 2005 Succinate links TCA cycle dysfunction to oncogenesis by inhibiting HIF-alpha prolyl hydroxylase. Cancer Cell 7 77-85. (doi:10.1016/j. ccr.2004.11.022)
Selak MA, Duran RV \& Gottlieb E 2006 Redox stress is not essential for the pseudo-hypoxic phenotype of succinate dehydrogenase deficient cells. Biochimica et Biophysica Acta 1757 567-572. (doi:10.1016/j.bbabio. 2006.05.015)

Strong VE, Kennedy T, Al-Ahmadie H, Tang L, Coleman J, Fong Y, Brennan M \& Ghossein RA 2008 Prognostic indicators of malignancy in adrenal pheochromocytomas: clinical, histopathologic, and cell cycle/apoptosis gene expression analysis. Surgery 143 759-768. (doi:10.1016/ j.surg.2008.02.007)

Thompson LD 2002 Pheochromocytoma of the adrenal gland scaled score (PASS) to separate benign from malignant neoplasms: a clinicopathologic and immunophenotypic study of 100 cases. American Journal of Surgical Pathology 26 551-566. (doi:10.1097/00000478200205000-00002)

Timmers HJ, Kozupa A, Eisenhofer G, Raygada M, Adams KT, Solis D, Lenders JW \& Pacak K 2007 Clinical presentations, biochemical phenotypes, and genotypephenotype correlations in patients with succinate dehydrogenase subunit B-associated pheochromocytomas and paragangliomas. Journal of Clinical Endocrinology and Metabolism 92 779-786. (doi:10.1210/ jc.2006-2315)

Tischler AS 2008 Pheochromocytoma and extra-adrenal paraganglioma: updates. Archives of Pathology \& Laboratory Medicine 132 1272-1284.

van Uden P, Kenneth NS \& Rocha S 2008 Regulation of hypoxia-inducible factor-1alpha by NF-kappaB. Biochemical Journal 412 477-484. (doi:10.1042/ BJ20080476)

Wu D, Tischler AS, Lloyd RV, DeLellis RA, de Krijger R, van Nederveen F \& Nose V 2009 Observer variation in the application of the pheochromocytoma of the adrenal gland scaled score. American Journal of Surgical Pathology 33 599-608. (doi:10.1097/PAS. 0b013e318190d12e) 